\title{
MARIÁTEGUI, PENSAMIENTO FRONTERIZO Y \\ TRANSMODERNIDAD: \\ UNA APROXIMACIÓN AL PROGRAMA DE INVESTIGACIÓN MODERNIDAD/COLONIALIDAD
}

\author{
HÉCTOR ALIMONDA ${ }^{1}$ \\ Universidade Federal Rural do Rio de Janeiro
}

¡Ya va a venir el día, repito, ponte el sueño!

César Vallejo, Poemas humanos

Uno de los aspectos más interesantes de la historia de las ideas políticas y sociales es la investigación genealógica de los antecesores, explícitos o implícitos, en el tratamiento de los problemas que en el "momento actual” devinieron cruciales, así como en la formulación de propuestas de acción reformadora. Esta investigación, que a veces adquiere contornos detectivescos, es mucho más desafiante y gratificante cuando se instala a partir de "epistemologías fronterizas", es decir, desde lugares teóricos (y con frecuencia, inclusive, territoriales) ajenos a las grandes tradiciones consolidadas de la geopolítica del pensamiento occidental.

Durante muchísimo tiempo, las grandes "religiones laicas" occidentales, el cristianismo, el liberalismo y el marxismo, pretendieron contener en sus cuerpos doctrinarios las respuestas a toda la diversidad de problemas creados y por crear por el desarrollo histórico. La tarea presente sería siempre la de releer los autores clásicos en búsqueda de su respuesta premonitoria a los desafios actuales. Por detrás de esa ortodoxia, lo sabemos, reposaba el presupuesto epistemológico y geopolítico de que esas magnas elaboraciones, construidas a partir de la experiencia histórica de algunas sociedades evolucionadas, expresaban en realidad el curso inexorable de un progreso humano que allí alcanzaba su clímax. No existirían problemas específicos de otras sociedades que no fueran los de

1

Também pesquisador internacional de Flacso Brasil: coordenador do Grupo de Trabalho em Ecologia Política, Conselho Latino-americano de Ciências Sociais; professor visitante do Doutorado em Ciências Sociais, Universidade de Buenos Aires. O autor agradece explícitamente os valiosos comentários e contribuições que este artigo recebeu do Dr. Ramón Grosfoguel, do Centro de Estudos Étnicos, Universidade da California/Berkeley. 
como adecuarlas mejor para recibir los estímulos dinamizadores de la modernidad.

La propia noción de "modernidad" está hoy en crisis, así como su vertiente operacional, la idea de "desarrollo". Esa crisis, sin duda, tiene como un elemento destacado el "colapso metabólico" entre el modelo productivo y energético de la sociedad industrial de consumo y la naturaleza planetaria, que se manifiesta hasta en las menores escalas locales. A la luz de esa crisis, el pensamiento social y político contemporáneo viene buscando no solamente respuestas, sino inclusive preguntas bien formuladas, que puedan orientar cursos de acción estratégica alternativa.

Las ciencias sociales latinoamericanas atraviesan un proceso de recomposición teórica, y nuestra intención es colaborar en ese proyecto colectivo con estas anotaciones sobre una relectura, a partir de claves actuales, de ese clásico permanente de la reflexión política y social del continente, que constituyen los Siete ensayos de interpretación de la realidad peruana, de José Carlos Mariátegui.

Hace unos años, en la introducción al primer libro producido por el Grupo de Trabajo en Ecologia Política, publicado por Consejo Latinoamericano de Ciencias Sociales (Clacso), arriesgamos la propuesta de un proyecto de elaboración colectiva que incluía la relectura del pensamiento social y político latinoamericano a partir de las claves ofrecidas por la crisis ambiental contemporánea (ALIMONDA, 2002:12). ${ }^{2}$ Aunque estas investigaciones, claro está, no permiten aún trazar una genealogía continua de un pensamiento latinoamericano de ecología política, iluminan, sin embargo, aspectos desconocidos de tradiciones intelectuales sobre las que creíamos que todo ya había sido dicho. Cada generación reescribe la historia a partir de su presente, y eso está sucediendo en América Latina en relación a las dimensiones ambientales y epistemológicas del pensamiento social y político.

\section{2}

“La tarea cada vez más urgente e imprescindible de construcción de una Ecologia Política latinoamericana debería recorrer esos caminos. Un esclarecimiento conceptural riguroso pero flexible, fundamentado en referentes teóricos críticos (...) Una relectura, desde nuevos puntos de vista, de clásicos del pensamiento social y político del continente, como José Bonifacio de Andrada e Silva, Manuel Gamio, José Martí, José Carlos Mariátegui o Gilberto Freyre. Y, sobre todo, un recuento de las desmesuradas experiencias de resistencia de los latinoamericanos, de su tozuda búsqueda de alternativas y de herencias, de sus esperanzas y de su desesperación, de sus sueños y de sus pesadillas." 
En esa dirección queremos aportar estas breves anotaciones sobre posibles experiencias de lectura de los Siete ensayos, a la luz de los aportes que están siendo reunidos por un proyecto colectivo emergente en la reflexión latinoamericana, el denominado "Programa de Investigación Modernidad/Colonialidad”. ${ }^{3}$ El intenso trabajo de revisión crítica que este colectivo está desarrollando, no ha incluido una aproximación específica a la obra de José Carlos Mariátegui, a pesar de que diferentes participantes han propuesto referencias altamente valorativas de la misma.

Desde nuestro punto de vista, los Siete ensayos se instalan precisamente en un lugar fronterizo. Por un lado, la sociedad peruana aparece como una trama articulada donde los elementos de modernidad refuerzan la sobrevivencia de la más consolidada opresión colonial del continente. En el plano económico, por ejemplo, los enclaves exportadores de la costa se combinan con la recomposición del latifundismo más tradicional en la sierra. Por otro lado, la crisis progresiva del orden político oligárquico no abre espacios políticos ni culturales alternativos para nuevos sectores sociales, una clase media urbana mestiza, que recibe y asimila las tendencias de cambio que llegan desde el escenario internacional, inclusive latinoamericano.

Coincidimos con Aníbal Quijano (1995, 2007), para quién la inspiración que orienta y fortalece la pasión de Mariátegui es la búsqueda de una racionalidad alternativa. Racionalidad alternativa ésta que no supone la negación de la modernidad y un regreso al mundo andino preconquista. Justamente la crítica de Mariátegui se instala en el espacio fronterizo de una "transmodernidad" (DUSSEL, 1994), que no niega la importancia de las conquistas materiales e intelectuales de la modernidad, pero que las impugna desde un punto de vista ético (para Enrique Dussel, 1995, allí reside lo más significativo de la lectura de Marx que realiza Mariátegui). Es a partir de esa impugnación que Mariátegui se propone recuperar el mundo andino, en tanto pasado que actualiza la posibilidad del socialismo en América (su tesis del "comunismo incaico"), pero especialmente como presente en la experiencia social, cultural y económica del campesinado indígena y de sus formas comunitarias de vida. ${ }^{4}$

3 En otra ocasión nos ocupamos de los aportes del grupo de la revista Amauta para una genealogia de la Ecologia Política latinoamericana (ALIMONDA, 2007a, 2007b, en publicación).

$4 \quad$ "El ayllu, célula del Estado incaico, sobreviviente hasta ahora, a pesar de los ataques de la feudalidad y del gamonalismo, aún tiene la fuerza suficiente para convertirse 
Escribe José Carlos Mariátegui en el artículo "La tradición nacional”, publicado en Mundial el 2 de diciembre de 1927:

Se puede decir del Perú lo que Waldo Frank dice de Norte América, que es todavía un concepto por crear. Más ya sabemos definitivamente, en cuanto al Perú, que este concepto no se creará sin el indio. El pasado incaico ha entrado en nuestra historia, reivindicado no por los tradicionalistas sino por los revolucionarios. En esto consiste la derrota del colonialismo, sobreviviente aún en parte como estado social (feudalidad, gamonalismo) pero batido para siempre como espíritu. La revolución ha reivindicado nuestra más antigua tradición (CARRIZO, 2007).

La revista Amauta, de crítica político-cultural internacional, con su boletín Labor, dedicado al seguimiento de las luchas de los movimientos sociales, será la expresión práctica de esta fusión entre tradición y modernidad, entre nacionalismo y cosmopolitismo, entre vanguardias diferenciadas pero igualmente enfrentadas con el régimen oligárquico y sus dispositivos represivos (GELADO, 2006).

\section{El "programa de investigación modernidad/colonialidad"}

El programa de investigación modernidad/colonialidad denominación adoptada por el antropólogo colombiano Arturo Escobar (2005:63) - consiste en un conjunto de elaboraciones convergentes que está siendo desarrollado desde hace unos años por una importante comunidad intelectual latinoamericana (Escobar caracteriza al programa como una "comunidad de argumentación", siguiendo al antropólogo brasileño Gustavo Lins Ribeiro). Sin poseer ninguna existencia institucional, es al mismo tiempo un dinámico espacio de intercambio y de realimentación de perspectivas analíticas, a partir de puntos de vista compartidos por estos intelectuales, que se desempeñan en centros académicos latinoamericanos y de Estados Unidos.

Un hito importante en la constitución de esta red fue un evento realizado en Caracas en 1998, organizado por Edgardo Lander, que reunió a varios intelectuales latinoamericanos que, por diferentes caminos,

gradualmente en la célula de un Estado socialista moderno", "Princípios de política agrária nacional”, Mundial, 1/7/1927. 
estaban alcanzando puntos de convergencia. Esa reunión dio origen a una publicación especialmente significativa, el libro La colonialidad del saber: eurocentrismo y ciencias sociales: perspectivas latinoamericanas, compilado por Edgardo Lander y editado por Clacso y por la Unidad Regional de Ciencias Sociales y Humanas de la Unesco (LANDER, 2000). Este volumen, de amplia circulación e influencia en los medios académicos de la región, incluye artículos de Santiago Castro-Gómez, Fernando Coronil, Enrique Dussel, Arturo Escobar, Edgardo Lander, Francisco López Segrera, Walter Mignolo, Alejandro Moreno y Aníbal Quijano, y presenta un panorama razonablemente completo de la propuesta colectiva del grupo, y de los desafíos teóricos y epistemológicos que lleva implícitos.

En julio de 2002, el antropólogo colombiano Arturo Escobar presentó un trabajo en el congreso de Ceisal en Amsterdam, realizando una presentación de la propuesta colectiva, a la que denominó “programa de investigación modernidad/colonialidad” (en adelante M/D). Se trata, desde luego, de un rótulo operacional, apropiado, pero absolutamente no institucionalizado. En esta presentación, Escobar desarrolla una breve genealogía de la gestación del proyecto colectivo y sus antecedentes, evalúa sus posiciones de ruptura en relación a otras interpretaciones o narrativas consagradas, presenta una síntesis concisa pero pertinente del entramado de puntos de lectura y de nociones organizadoras de la reflexión colectiva, propone, por último, líneas posibles de elaboración a partir de áreas temáticas aún poco transitadas por las reflexiones vinculadas al proyecto: género, naturaleza (incluyendo aquí nuestro Grupo de Trabajo de Clacso), experiencias alternativas de economía popular (ESCOBAR, 2005).

Otro intento de presentación sintetizadora de la experiencia y de sus perspectivas fue realizado por el colombiano Santiago Castro-Gómez y el puertorriqueño Ramón Grosfoguel, en el prólogo a un libro publicado en Colombia, reuniendo varios artículos de participantes asiduos del programa y de allegados más recientes (CASTRO-GÓMEZ y GROSFOGEL, 2007). En este trabajo, es importante el deslinde que los autores realizan entre el programa M/D y otras perspectivas contemporáneas de las ciencias sociales relativamente afines, como la crítica post-colonial, los estudios culturales de raíz post-estructuralista y la concepción del "sistema/mundo". 5

5 En comunicación personal por correo electrónico (10/9/2008), Ramón Grosfoguel aporta otros elementos para esta genealogía: "Los eventos y discusiones sobre 
A los efectos de este trabajo, optamos por seguir como referencia la presentación realizada por Arturo Escobar. Para Escobar, lo distintivo del proyecto colectivo es el intento de intervención decisiva en la discursividad propia de las ciencias sociales para configurar otro espacio para la producción de conocimiento, "una forma distinta de pensamiento, um paradigma otro, la posibilidad de hablar sobre mundos y conocimientos de otro modo" (ESCOBAR, 2005:64).

Veamos la presentación que hace Escobar del núcleo central del programa M/D:

La conceptualización de la modernidad/colonialidad se apoya en una serie de operaciones que la distinguen de las teorías establecidas de la modernidad. Planteado sucintamente, éstas incluyen las siguientes: 1) un énfasis en localizar los orígenes de la modernidad en la conquista de América y el control del Atlántico después de 1492, antes que en la Ilustración o el final del siglo XVIII, como es comúnmente aceptado; 2) una atención persistente al colonialismo y al desarrollo del sistema mundial capitalista como constitutivos de la

el tema comenzaron en Puerto Rico en los ochenta y más tarde en la Universidad del Estado de Nueva York en Binghtamton en los noventa, donde Quijano pasa estancias de seis semanas anualmente desde hace casi ya tres décadas. En Binghamton entra en contacto con un grupo de puertorriqueños con los que comenzó a hacer seminarios y discusiones a profundidad del tema de la colonialidad del poder y del saber. Esto desde principios de los noventa, mucho antes del evento en Montreal que dio pie al libro La colonialidad del saber, que edita Lander. No digo esto por un identity politics de reconocimiento o por un nacionalismo puertorriqueño. Lo digo porque la perspectiva de la colonialidad no es un pensamiento continental (por ejemplo: latinoamericano, africano, europeo, asiático, etc.). El pensamiento continental es todavía una construcción de la colonialidad del poder y en el caso de América Latina es todavía un pensamiento de las elites criollas blancas de izquierda o de derecha. El pensamiento de la colonialidad del poder y la perspectiva decolonial surge de la influencia de la perspectiva geopolítica y corpo-política del conocimiento de minorías racializadas en los Estados Unidos (sobretodo latinos y también afro-americanos) y en América Latina (perspectiva indígena, negra y mestiza). Esto es importante, porque la perspectiva de la colonialidad no es 'latinoamericana' ni tampoco 'norteamericana', es una perspectiva decolonial de desprendimiento que surge de la perspectiva epistémica de sujetos racializados, en contextos de inferiorización. Tanto la transdisciplinariedad como la perspectiva desde los condenados de la tierra o Calibán son fundamentales para el pensamiento de la colonialidad del poder o decolonial”. 
modernidad; esto incluye la determinación de no pasar por alto la economía y sus concomitantes formas de explotación; 3) en consecuencia, la adopción de una perspectiva planetaria en la explicación de la modernidad, en lugar de una visión de la modernidad como un fenómeno intra-europeo; 4) la identificación de la dominación de otros afuera del centro europeo como una necesaria dimensión de la modernidad, con la concomitante subalternización del conocimiento y las culturas de esos grupos; 5) la concepción del eurocentrismo como la forma de conocimiento de la modernidad/colonialidad, una representación hegemónica y un modo de conocimiento que arguye su propia universalidad, y que descansa en una confusión entre una universalidad abstracta y el mundo concreto derivado de la posición europea como centro" (ESCOBAR, 2005:70-71).

La genealogía del pensamiento del programa $M / D$ se nutre de evidentes raíces en la historia de las ideas latinoamericanas, que son recordadas por Escobar: la teoría de la dependencia, la teología de la liberación:

(...) los debates en la filosofía y la ciencia social latinoamericana sobre nociones como filosofía de la liberación y una ciencia social autónoma, los debates sobre la modernidad y la post-modernidad en los ochenta, seguidos por las discusiones sobre la hibridad en antropología, comunicación y estudios culturales en los noventa y, en los Estados Unidos, el grupo latinoamericano de estudios subalternos. Su principal fuerza orientadora, sin embargo, es una reflexión continuada sobre la realidad cultural y política latinoamericana, que incluye el conocimiento subalternizado de los grupos explotados y oprimidos. Si se puede decir que la teoría de la dependencia, la teología de la liberación y la investigación acción participativa han sido las contribuciones más originales de Latinoamérica al pensamiento crítico en el siglo XX, el programa de investigación M/D emerge como el heredero de esta tradición (ESCOBAR, 2005:64).

En realidad, nada hay a objetar a esta lista de "herencias presentes" que Escobar enumera. Lo que llama la atención, y para eso no hace falta ser "especialista mariateguiano" es la ausencia de referencias no solamente a Mariátegui, sino al conjunto de preocupaciones comunes a su generación 
política e intelectual (incluyendo, naturalmente, a Victor Raúl Haya de la Torre), presentes en el ideario continental de la Reforma Universitaria y heredero, a su vez, de una epistemología política que fácilmente puede remontarse a José Martí y al clima de ideas entre los sectores políticos “progresistas” del pasaje del siglo XIX al XX, al que Oscar Terán llamó “el primer antimperialismo latinoamericano" (TERÁN, 1986). Un conjunto político-intelectual complejo y contradictorio, es verdad, pero no tan inconsecuente como para justificar el silencio que sobre esa época mantienen quienes han escrito sobre la genealogia del proyecto M/D. Nuestra intención es justamente aprovechar la realización de este evento para llamar la atención sobre ese silencio y apuntar la dirección de algunos puentes posibles entre la obra de José Carlos Mariátegui y el proyecto $\mathrm{M} / \mathrm{D}$, esperando que puedan ser construidos por otros investigadores (no solamente en relación a José Carlos, sino al conjunto de su generación, sin duda los primeros "americocéntricos" desde los tiempos bolivarianos) ${ }^{6}$ Este proyecto, en realidad, fue esbozado por Aníbal Quijano en una nota de su introducción a la tercera edición de los Siete ensayos en la Biblioteca Ayacucho: 'En unas breves notas para una nueva publicación de los 7 ensayos, sería pertinente abrir un debate sobre las implicaciones de todos estos movimientos de ruptura con el eurocentrismo en la obra de Mariátegui” (QUIJANO, 2007:CXXVI).

Para Quijano, en los Siete ensayos tiene lugar una primera y decisiva ruptura con el eurocentrismo:

\section{(...) y asume el carácter de toda una subversión epistémica y teórica, puesto que es producida dentro de la misma perspectiva formalmente admitida por Mariátegui, el materialismo histórico y la perspectiva de una secuencia}

6

Existe también un antecedente genealógico en la obra de Claude Lévi-Strauss. Se trata del pequeno artículo "Las descontinuidades culturales y el desarrollo econômico", una comunicación presentada em una reunión del Consejo Internacional de Ciencias Sociales en 1961 (LÉVI-STRAUSS, 1976). Lévi-Strauss no solamente presenta una crítica vigorosa a la modernidad a partir de su antecedente colonial, como remite esa perspectiva al tratamiento de la acumulación originaria por Marx, en el capítulo XXIV de El capital. Allí, en efecto, Marx considera a la constitución de una periferia colonial entre los puntos de partida de la acumulación capitalista, pero avanza más, incluyendo a la esclavitud colonial como la condición necesaria para la viabilización de la explotación propiamente capitalista de los trabajadores en las metrópolis: "En general, la esclavitud encubierta de los obreros asalariados en Europa exigía, como pedestal, la esclavitud 'sans phrase’ en el Nuevo Mundo” (MARX, 1971, v. I:646). 
evolutiva de modos de producción y en el mismo intento de emplearla: "Apuntaré una constatación final: la de que en el Perú actual coexisten elementos de tres economías diferentes. Bajo el régimen de economía feudal nacido de la Conquista, subsisten en la sierra algunos residuos vivos todavía de la economía comunista indígena. En la costa, sobre un suelo feudal, crece una economía burguesa que, por lo menos por su desarrollo mental, da la impresión de una economía retardada”. Esa perspectiva rompe, primero, con la idea eurocéntrica de totalidad y con el evolucionismo, que presuponen una unidad continua y homogénea, aunque contradictoria (...) Esa subversión epistémica y teórica original podría reconocerse como la fuente de la producción de la idea latinoamericana de heterogeneidad históricoestructural, rompiendo de ese modo con el dualismo radical del cartesianismo, que está en el origen mismo del eurocentrismo y con las propensiones positivistas al reduccionismo y al evolucionismo. Y sin ese nuevo punto de partida no podríamos explicar el nuevo debate teórico y político, dentro y fuera de América Latina, sobre el carácter y la historia del actual poder mundial, en especial el activo debate en torno de la propuesta teórica de la colonialidad y des/colonialidad del poder (QUIJANO, 2007:CXXVICXXVIII).

Otra interpretación de la genealogía del programa M/D es propuesta por uno de sus más importantes contribuyentes, el argentino Walter Mignolo. Para Mignolo, “desde el fin de la guerra fría, el pensamiento descolonial comienza a trazar su propia cronología. El propósito de este texto es contribuir a ese trazado" (2006:88). El núcleo de la propuesta, el resumen de la plataforma del proyecto modernidad/colonialidad, estaría contenido, para Mignolo, en un artículo pionero de Aníbal Quijano, redactado en ocasión del Quinto Centenario:

La crítica del paradigma europeo de la racionalidad/modernidad es indispensable. Más aún, urgente. Pero es dudoso que el camino consista en la negación simple de todas sus categorías, en la disolución de la realidad en el discurso, en la pura negación de la idea y de la perspectiva de totalidad en el conocimiento. Lejos de ésto, es necesario desprenderse de las vinculaciones de la racionalidadmodernidad con la colonialidad, en primer término, y en 
definitiva con todo poder no constituido en la decisión libre de gentes libres. Es la instrumentalización de la razón por el poder colonial, en primer lugar, lo que produjo paradigmas distorsionados de conocimiento y malogró las promesas liberadoras de la modernidad. Por consecuencia, la alternativa es clara: la destrucción de la colonialidad del poder mundial (QUIJANO, 1992, apud MIGNOLO, 2006). ${ }^{7}$

Para Mignolo, el objetivo central del proyecto $\mathrm{M} / \mathrm{D}$ es la recuperación del pensamiento des-colonial, que emerge justamente a partir de la implantación del colonialismo como la cara necesaria (y necesariamente oculta) de la modernidad europea. Ese pensamiento descolonial se erige en situación "fronteriza", a partir de una exterioridad que no es absoluta, sino que está constituida por una situación de subalternización establecida por la colonialidad. La modernidad se elabora como constituyente de una identidad europea, como centro dinámico de la historia universal y clave de su desarrollo y fuente organizadora de todo conocimiento válido. De allí su carácter eurocéntrico. Mediante el "giro des-colonial", algunos subalternizados establecen una identidad de frontera, a partir de la cual impugnan al proyecto moderno/colonial desde un dentro/afuera. No se trata de las rebeliones o ataques desde el exterior (como las imágenes míticas de los bárbaros atacando a Roma o los gauchos al proyecto urbano-céntrico de Sarmiento), sino de una enunciación desde un otro lugar, que coteja el proyecto moderno con la realidad de la dominación colonial y de su violencia, y que lo impugna en nombre de la irrealidad de sus promesas incumplidas.

Desde este punto de vista, es claro que para Mignolo el giro descolonial acompaña a la modernidad/colonialidad desde la conquista de América. Superada la violencia inmediata de los primeros años de la Conquista, cuando se ha producido una relativa estabilización de nuevas relaciones sociales y un progresivo conocimiento mutuo entre dominantes y subalternizados. América indígena es la primera periferia colonial de la

7

Propone también Quijano en el artículo citado: "En primer término, es necesaria la descolonización epistemológica, para dar paso luego a una nueva comunicación intercultural, a un intercambio de experiencias y de significaciones, como la base de otra racionalidad que pueda pretender, con legitimidad, alguna universalidad. Pues nada menos racional, finalmente, que la pretensión de que la específica cosmovisión de una etnia particular sea impuesta como la racionalidad universal, aunque tal etnia se llame Europa Occidental. Porque eso, en verdad, es pretender el título de universalidad para un provincialismo" (QUIJANO, 1992, apud MIGNOLO, 2006:93). 
modernidad europea. Es, en verdad, la situación colonial de América lo que le permitirá a Europa Occidental enfrentar a sus seculares enemigos musulmanes y transformarse en la potencia colonizadora por excelencia. Siendo así, Mignolo identifica en el discurso de Waman Poma de Ayala al primer antecedente conocido del pensamiento des-colonial. ${ }^{8}$ Dice Mignolo:

\begin{abstract}
Waman Poma y Otabbah Cugoano abrieron un espacio-otro, el espacio del pensamiento des-colonial, em la diversidad de las experiencias a las que los seres humanos fueron forzados por las invasiones europeas en estos dos casos. Me detendré en ellos como los fundamentos (semejantes a los fundamentos griegos para el pensamiento occidental) del pensamiento descolonial. Estos fundamentos históricos crean las condiciones para una narrativa epistémica que enlace la genealogía global del pensamiento des-colonial hasta Mahatma Gandhi, W.E.B. Dubois, José Carlos Mariátegui, Amílcar Cabral, Aimé Cessaire, Frantz Fanon, Fausto Reinaga, Vine Deloria Jr., Rigoberta Menchú, Gloria Ansaldúa, el Movimiento Sin Tierras en Brasil, los zapatistas en Chiapas, los movimientos indígenas y afros en Bolivia, Ecuador, Colombia, el Foro Social Mundial y el Foro Social de las Américas. La genealogía del pensamiento descolonial es planetaria y no se limita a individuos, sino que se incorpora en movimientos sociales y en la creación de instituciones (2006:101-102).
\end{abstract}

El otro autor que es inspirador fundamental del programa $M / D$, el filósofo argentino Enrique Dussel, reconoce y valora la importancia de José Carlos Mariátegui (DUSSEL, 1990:281-283; 1995). Aunque sea en pocas páginas, Dussel rescata la continuidad de Mariátegui en relación al Marx de la madurez, donde es a partir de una realidad histórica concreta (en su caso, la peruana y latinoamericana) que se accede a la elaboración teórica. Destaca que la prioridad otorgada a la interpretación económica por parte de Mariátegui no lo lleva nunca a caer en el economicismo, reivindica su percepción del carácter ético de la crítica teórica, su concepción de la política como una articulación práctica de una pluralidad en construcción, su comprensión de la cuestión nacional en los países

8

El esclavo liberto Otabbah Cugoano, quién publicó en 1787, en Londres, un tratado sobre la perfidia de la esclavitud, tendría el mismo lugar que Waman Poma en relación al imperio británico, por lo menos en lo que se refiere a sus colonias esclavistas del Caribe (MIGNOLO, 2006:89). 
periféricos, diferenciada del nacionalismo imperialista, y su valorización de la problemática indígena como prioritaria en un proyecto socialista.

Entre los aportes genealógicos que Dussel destaca para el punto de vista del programa M/D se incluye una vasta recuperación de la cosmovisión y de la resistencia de los pueblos indígenas americanos, y la selección de Fray Bartolomé de las Casas como el primer enunciador de una crítica a la modernidad eurocéntrica.

En resumen: a pesar de la potencialidad y fertilidad de los contenidos de la obra mariateguiana para la perspectiva del programa M/D, la misma no ha sido recuperada como un antecedente destacado por los principales inspiradores de este proyecto colectivo, con excepción de Aníbal Quijano. Significativamente, tampoco son recuperados el proyecto de Amauta, el aprismo original o el clima de ideas de la época. Trataremos, aunque sea en forma breve, de sugerir algunas conexiones que nos parecen pertinentes entre la obra de José Carlos Mariátegui y algunas nociones estratégicas del programa de investigación M/D.

\section{Traducciones de Mariátegui}

En la manera de breves indicaciones, tomaremos algunas de las nociones claves, según Escobar, del programa M/D, y comentaremos la forma en que la obra de José Carlos Mariátegui se adecua a las mismas.

Exterioridad: La pregunta por la existencia de una "exterioridad" con respecto al sistema mundo moderno es peculiar a este grupo y fácilmente malentendida. Fue originalmente propuesta y elaborada cuidadosamente por Enrique Dussel en su clásico trabajo sobre la filosofía de la liberación (1976) y reelaborada en los recientes años. De ninguna manera esta exterioridad debe ser pensada como un puro afuera intocado por lo moderno. La noción de exterioridad no implica un afuera ontológico, sino que se refiere a un afuera constituido como diferencia por el discurso hegemónico. Esta noción de exterioridad surge principalmente del pensamiento sobre el Otro, desde la perspectiva ética y epistemológica de la filosofía de la liberación: el Otro como oprimido, como mujer, como racialmente marcado, como excluido, como pobre, como naturaleza (ESCOBAR, 2005:74). 
En este punto, parece evidentemente innecesario pretender demostrar nada menos que en un evento mariateguiano, que la visión que Mariátegui tiene del problema indígena corresponde exactamente a la noción de exterioridad utilizada por Dussel y por extensión, por la comunidad intelectual del programa M/D. La situación de los indígenas, en época de Mariátegui, no es interpretada en términos de exclusión en abstracto, sino como una subalternización que implica la explotación económica, la dominación política y la invisibilización cultural.

Transmodernidad: esta noción utilizada por Enrique Dussel, es atribuída a Fray Bartolomé de las Casas, "como fundador de un contradiscurso filosófico explícito como un proyecto de transmodernidad desde la otra cara del mundo/modernidad, desde el Otro, América Latina, África y Asia, mujeres oprimidas, tierra destruida como medio de producción” (1996:152, nota 40). La crítica al mito civilizatorio de la modernidad y el desenmascaramiento de la violencia colonial que lleva implícita abre la posibilidad de recuperar desde otro lugar a la potencialidad emancipatoria de la razón moderna.

De esta manera, la razón moderna es trascendida, pero no
como negación de la razón en cuanto tal, sino de la razón
violenta eurocéntrica, desarrollista, hegemónica. Se trata de
una Transmodernidad como proyecto mundial de liberación,
donde la Alteridad, que era co-esencial de la Modernidad, se
realice igualmente. La realización sería ahora el pasaje
trascendente, donde la Modernidad y su Alteridad negada (las
víctimas), se co-realizarán por mutua fecundidad creadora,
imposible para la sola Modernidad: es decir, es co-realización
de solidaridad, que hemos llamado analéctica, del
Centro/Periferia, Mujer/Varón, diversas razas, diversas etnias,
diversas clases, Humanidad/Tierra, Cultura
occidental/Culturas del Mundo Periférico ex colonial, etc., no
por pura negación, sino por incorporación desde la Alteridad
(DUSSEL, 2000:50; en el mismo sentido, DUSSEL,
1994:177 y 2002).

En este punto, nos encontramos plenamente con una idea reiteradamente expuesta por Aníbal Quijano (1995:39-47; 2007). El marxismo de Mariátegui (y el secreto de su vigor y de su originalidad) reposa precisamente en haber comprendido que el núcleo dinámico de la crítica de Marx al capitalismo consistía en la búsqueda de una racionalidad alternativa. 
Si es así, a partir del punto de partida de una realidad nacional latinoamericana, con su densidad histórica y su heterogeneidad plurifacética, la apuesta que impulsa la búsqueda apasionada de Mariátegui es la posibilidad de convocar a "todas las sangres" para la construcción de una modernidad alternativa, recuperando, inclusive, a las tradiciones indígenas sobrevivientes en sus formas de vida comunitaria. Por eso la operación necesaria de erigir al mundo incaico en experiencia socialista. La forma social más tradicional y más antigua del Perú pasaba a ser, al mismo tiempo, una promesa de modernidad. Como dijo Antonio Cornejo Polar (1993), Mariátegui arriesga:
(...) la apuesta a favor de una modernidad que no fuera copia de la alcanzada por los países centrales, incluyendo los estados socialistas nacientes en esa coyuntura, sino desarrollo peculiar de diversas circunstancias socio-histórico-culturales. En este caso, una modernidad andina. En tal sentido, mientras que hoy se hace cada vez más común pensar que la modernidad de los países andinos depende de su capacidad de “desindigenización”, la tesis mariateguiana propone una alternativa antidogmática: no hay una sino muchas modernidades, y varias maneras de llegar a ese punto, y dentro de ellas es insensato no incluir la opción de imaginar y realizar una modernidad de raíz y temple andinos.

Por eso, continua Cornejo Polar, el socialismo latinoamericano no podía ser calco ni copia, sino creación heroica, al que se le daría vida con la propia realidad, con el propio lenguaje. Es decir, sería la creación de una sociedad peruana reconciliada consigo misma, y autoconstruyéndose a partir de su propia dinámica, siguiendo su propio camino de modernización, hacia su identidad futura (CORNEJO POLAR, 1993:60$61)$.

Para otro destacado mariateguiano, César Germaná, en Mariátegui:

(...) el socialismo no era, pues, la continuación y el
coronamiento de la sociedad del trabajo que había surgido
con el capitalismo; lo concebía como otra forma de
racionalidad, no centrada en la técnica y el beneficio, sino en
la solidaridad y la comunicación. Más aún, pienso que esta
idea constituía el substrato más profundo de sus reflexiones y
el elemento que suponía, abarcaba y daba sentido a los otros
aspectos del socialismo, la socialización de los recursos de 
producción y la socialización del poder político. Se trata, por lo tanto, del núcleo alrededor del cual se articula el pensamiento de José Carlos Mariátegui (GERMANÁ, 1995:171).

Epistemología de frontera/Giro des-colonial: "Des-colonial es el concepto que toma el lugar, en otra genealogía del pensamiento, del concepto 'crítico' en el pensamiento moderno de disenso en Europa" (MIGNOLO, 2006:83). Supone una ruptura con la concepción hegemónica de la modernidad, que cuestiona su necesidad histórica y descubre su geopolítica de enunciación de narrativas y de producción de conocimientos. Y también a la violencia y a la invisibilización implícitas. Ese movimiento, ese umbral, esa línea de sombra imperceptible, pero a partir de la cual todo es visto a partir de una óptica diferente, constituye el giro des-colonial. A partir del giro des-colonial se establece un nuevo lugar de enunciación, fronterizo. Se habla sobre la modernidad, pero no desde ella, se habla desde un lugar ambiguo, pero cuya perspectiva es casi panóptica. Pero atención: la importancia del giro des-colonial en Mariátegui está resaltada porque no se limita a incorporar a su marxismo una teoría del imperialismo post-leninista. En realidad, el giro des-colonial de Mariátegui lo aleja también de las categorías de un marxismo clásico que no puede hacer pie en la historicidad concreta de lo americano, y lo lleva a proponer ese socialismo indo-americano, a partir de la vigencia del pasado autóctono.

Tampoco será necesario insistir demasiado en que el enunciador Mariátegui es el propio sujeto trans-fronterizo. Está ávidamente dispuesto a apropiarse de todo el repertorio de la Modernidad (todo lo humano es nuestro), en una perspectiva que recuerda al antropófago Oswald de Andrade, pero para ponerla al servicio, para operacionalizarla como elemento de construcción de una identidad nacional. Es a partir de su enraizamiento en la realidad nacional que propone el más actual cosmopolitismo. ${ }^{9} \mathrm{Y}$, desde luego, su enunciación se instala en la más amplia trans-disciplinariedad, que le permite, por ejemplo, insistir sobre el carácter decisivo de las determinaciones económicas sin caer nunca en el economicismo. Su carácter de sujeto fronterizo lo acompaña desde los tiempos de la bohemia, de aquella su Edad de Piedra, y siempre mantendrá su valoración de la religión y del misticismo como elemento esencial para un proceso revolucionario. Hay en su vida un giro social, cuando como

9

Por eso el crítico brasileño Alfredo Bosi (1992) se refiere a Mariátegui y a sus compañeros de generación con la denominación paradójica de "la vanguardia enraizada". 
periodista se compromete con la lucha obrera por la jornada de ocho horas y con la Reforma Universitaria. Hay un giro nacional, cuando por los caminos de Europa descubre su pertenencia al mundo americano. Y el giro descolonial?

Hace unos años, arriesgamos la hipótesis de la localización cronológica exacta de ese giro des-colonial (ALIMONDA, 1994). Repetiremos brevemente el argumento. El 28 de noviembre de 1924, la revista Mundial publica su artículo "Lo nacional y lo exótico”. Allí aparece explícitamente su visión de lo nacional como un proceso en construcción, pero a partir de una perspectiva eurocéntrica: “El Perú es una nacionalidad en formación. Está siendo construido sobre los inertes estratos indígenas por los aluviones de la sociedad occidental”.

Lo que resulta sorprendente es que unos pocos días más tarde, el 9 de diciembre, esa misma revista Mundial publica otro artículo de Mariátegui, donde desde el título abrupto, "El problema primario del Perú" se presenta una ruptura radical con sus concepciones anteriores. Su discurso se abre ahora para una perspectiva de reivindicación del elemento indígena no sólo como fundamento de la nacionalidad, sino también como actor central de una propuesta política de transformación, nueva visión que Mariátegui no abandonará hasta su muerte. Comienza por situar lo indígena en la multitud de determinaciones que lo constituyen en la formación social peruana, como agente económico, político y cultural (es decir, como clase).

El cuerpo de este artículo será reproducido después textualmente en uno de los Siete ensayos, "El problema del indio". Contiene, con excepción del tema fundamental de las comunidades campesinas, lo esencial del pensamiento de Mariátegui en relación a la cuestión indígena. Propusimos entonces la idea de que existiría una "significativa ruptura" (que hoy llamaríamos "giro des-colonial" en el pensamiento de Mariátegui, delineada en esos textos y localizada en noviembre/diciembre de 1924. Desde entonces, se redefine toda su concepción de la cuestión indígena, que aparecerá como un principio articulador central de sus lecturas sobre la cuestión de la nacionalidad, del sentido de la historia peruana, de su visión de la modernidad y de las estrategias de organización política de las fuerzas populares. En términos de Dussel, diríamos que Mariátegui ha descubierto no solamente la colonialidad detrás de la modernidad, sino la propia posibilidad de la transmodernidad.

Un texto posterior ayuda a "situar" esa ruptura. Se trata de "Vidas paralelas: E. D. Morel - Pedro Zulen”, publicado en Mundial el 6 de febrero de 1925, donde Mariátegui presenta un paralelismo entre los 
ideales de estos dos hombres recientemente fallecidos: un inglés pacifista y anti-imperialista, un peruano luchador por las reivindicaciones indígenas. Entre sus recuerdos de Pedro Zulen está el siguiente pasaje:

\section{(...) recuerdo otro encuentro más emocionado todavía: el encuentro de Pedro Zulen y de Ezequiel Urviola, organizador y delegado de las federaciones indígenas del Cuzco, en mi casa, hace tres meses. Zulen y Urviola se complacieron recíprocamente de conocerse. El problema indígena, dijo Zulen, es el único problema del Perú.}

Según este registro del propio Mariátegui, la velada en la casa de la calle Washington izquierda habría sucedido tres meses antes de febrero de 1925. Es decir, precisamente en noviembre de 1924. A ella pueda atribuirse, quizás, la ruptura que observamos, en la forma de "giro descolonial” en el pensamiento de José Carlos Mariátegui. Es posible que el impacto de ese encuentro entre ambos campeones de la causa indígena haya tenido un papel decisivo en la significativa alteración de las claves de lectura de Mariátegui, que ya sería definitiva (ALIMONDA, 1994).

\section{MARIÁTEGUI, PENSAMENTO FRONTERIÇO E TRANSMODERNIDADE: UMA APROXIMAÇÃO AO PROGRAMA DE INVESTIGAÇÃOMODERNIDADE/COLONIALIDADE}

Resumo: A oitenta anos da publicação dos Sete ensaios de interpretação da realidade peruana, de José Carlos Mariátegui, este artigo tenta interrogar essa obra desde as perspectivas contemporâneas da Ecologia Política e do Projeto Modernidade/Colonialidade.

Palavras-chave: José Carlos Mariátegui; Sete ensaios de interpretação da realidade peruana; Ecologia Política; Projeto Modernidade/Colonialidade.

\section{MARIÁTEGUI, BORDER'S THINKING AND TRANSMODERNITY: AN APPROACH TO THE RESEARCH PROGRAM MODERNITY/COLONIALITY}

Abstract: Eighty years after its publication, the Seven interpretative essays on Peruvian reality, work of José Carlos Mariátegui, can be read and asked from contemporary points of view, as Political Ecology and the Modernity/Coloniality Project.

Keywords: José Carlos Mariátegui; Seven interpretative essays on Peruvian reality; Political Ecology; Modernitiy/Coloniality Project. 


\section{BIBLIOGRAFIA}

ALIMONDA, Héctor (1983). José Carlos Mariátegui: redescobrir a América. São Paulo: Brasiliense.

. (1994). Mariátegui y las vanguardias, la tradición y la modernidad. Anuario Mariateguiano, Lima, v. VI, n. 6.

. (Comp.) (2002). Ecología política: naturaleza, sociedad y utopía. Buenos Aires: Clacso.

. (2007a). Una ecología política en Amauta? Buscando una herencia en Lima. In: Anales del Segundo Simposio Internacional Amauta y su Época. Lima, ago. 2006. Lima: Ed. Viuda de Mariátegui e Hijos S.A.

. (2007b). La ecología política de Mariátegui. Tareas, Panamá, 125, enero/abr.

. (en publicación). Una ecología política en la revista Amauta? Notas para una arqueología del ecologismo socialista latinoamericano. En publicación en libro organizado por Maria Luisa Eschenhagen para la Universidad Central, Bogotá.

BOSI, Alfredo (1992). La vanguardia enraizada: el marxismo vivo de Mariátegui. Anuario Mariateguiano, Lima, v. VI, n. 4.

CARRIZO, Silvina Liliana (2007). Los años 20 y la discusión sobre la tradición. In: Anales del Segundo Simposio Internacional Amauta y su Época. Lima, ago. 2006. Lima: Ed. Viuda de Mariátegui e Hijos S.A.

CASTRO-GÓMEZ, Santiago; GROSFOGEL, Ramón (Eds.) (2007). El giro decolonial: reflexiones para una diversidad epistémica más allá del capitalismo global. Bogotá: Universidad Javeriana; Universidad Central; Siglo del Hombre.

CORNEJO POLAR, Antonio (1993). Mariátegui y su propuesta de una modernidad de raíz andina. Anuario Mariateguiano, Lima, v. V, n. 5.

DUSSEL, Enrique (1990). El último Marx (1863-82) y la liberación latinoamericana. México: Siglo XXI.

. (1994). 1492: el encubrimiento del otro. La Paz: Plural Editores; Facultad de Humanidades y Ciencias de la Educación, Universidad Nacional Mayor de San Andrés.

(1995). El marxismo de Mariátegui como filosofía de la revolución. In: VARIOS AUTORES. El marxismo de José Carlos Mariátegui. V Congreso Nacional de Filosofía. Lima: Universidad de Lima; Amauta. . (1996). The underside of modernity. New Jersey: Humanities Press. 
- (2000). Europa, modernidad y eurocentrismo. In: LANDER, Edgardo (Comp.). La colonialidad del saber: eurocentrismo y ciencias sociales. Buenos Aires: Clacso; Unesco.

. (2002). World system and trans-modernity. Nepantla, 3.2.

ESCOBAR, Arturo (2005). Mundos y conocimientos de otro modo: el programa de investigación modernidad/colonialidad. In: Más allá del Tercer Mundo: globalización y diferencia. Santafé de Bogotá: Instituto Colombiano de Antropología e Historia; Universidad del Cauca.

GELADO, Viviana (2006). Poéticas da transgressão: vanguarda e cultura popular nos anos 20 na América Latina. Rio de Janeiro: 7 Letras; São Carlos: Ed. UFSCar.

GERMANÁ, César (1995). El socialismo indo-americano de José Carlos Mariátegui. Lima: Amauta.

LANDER, Edgardo (Comp.) (2000). La colonialidad del saber: eurocentrismo y ciencias sociales. Buenos Aires: Clacso; Unesco.

LÉVI-STRAUSS, Claude (1976). As descontinuidades culturais e o desenvolvimento econômico. In: Antropologia estrutural II. Rio de Janeiro: Tempo Brasileiro.

MARIÁTEGUI, José Carlos (1994). Mariátegui total. Lima: Amauta.

MARX, Carlos (1971). El capital. México: Fondo de Cultura Económica.

MIGNOLO, Walter (2006). El pensamiento des-colonial, desprendimiento y apertura: un manifiesto. In: WALSH, Catherine. Interculturalidad, descolonización del Estado y del conocimiento. Buenos Aires: Ediciones del Signo.

QUIJANO, Aníbal (1995). El marxismo en Mariátegui: una propuesta de racionalidad alternativa. In: VARIOS AUTORES. El marxismo de José Carlos Mariátegui. Lima: Amauta.

. (2007). José Carlos Mariátegui: reencuentro y debate. Prólogo. In: MARIÁTEGUI, José Carlos. Siete ensayos de interpretación de la realidad peruana. Caracas: Biblioteca Ayacucho.

TERÁN, Oscar (1986). En busca de la ideología argentina. Buenos Aires: Catálogos. 